\title{
The influence of symptoms of anxiety and depression on medication nonadherence and its causes: a population based survey of prescription drug users in Sweden
}

\author{
This article was published in the following Dove Press journal: \\ Patient Preference and Adherence \\ 17 August 2013 \\ Number of times this article has been viewed
}

\author{
Lena Thunander Sundbom ${ }^{1,2}$ \\ Kerstin Bingefors ${ }^{2}$ \\ 'Faculty of Health and Occupational \\ Studies, Department of Health \\ and Caring Sciences, University \\ of Gävle, Gävle, Sweden; \\ ${ }^{2}$ Pharmacoepidemiology and \\ Pharmacoeconomics, Department \\ of Pharmacy, Uppsala University, \\ Uppsala, Sweden
}

Purpose: The purpose of this study was to evaluate the associations between self-reported symptoms of anxiety and/or depression, nonadherent (NA) behaviors, and reasons for NA to medication regimens.

Methods: A population based cross-sectional study with questionnaire was performed in the general Swedish population. The participants were 2,802 prescription drug users aged 18-84 years. The questionnaire covered use of prescription drugs, symptoms of anxiety and/or depression, based on the Hospital Anxiety and Depression Scale (HADS), various NA behavior types, intentional and unintentional, and various reasons for NA.

Results: Symptoms of anxiety and depression, independently and in combination, were associated with unintentional and intentional NA, with a stronger association with intentional NA. Regarding the reasons given for NA, for example anxiety, independently or in combination with depression, was associated with a fear of developing adverse drug reactions (ADRs). Depression, independently or in combination with anxiety, on the other hand, was associated with the actual development of ADRs.

Conclusion: A cross-sectional design such as this does not allow assessment of causality derived from the results. However, the results indicate that patients experiencing symptoms of psychological distress are at increased risk of NA, especially intentional NA, and could therefore benefit from extra attention from the health care professional. Patients with symptoms of anxiety and/or depression should be identified and monitored for the development and/or fear of ADRs, in order to improve adherence to medication regimens.

Keywords: medication adherence, anxiety symptoms, depression symptoms, reasons

\section{Introduction}

Nonadherence (NA) to medication regimens is the dilemma of every health care professional. Up to $50 \%-60 \%$ of all patients show poor medication adherence and NA is considered the most common reason for treatment failure. ${ }^{1,2}$ NA can be either unintentional (eg, forgetting to take the medication) or intentional (a more active decision that can involve changing the dosage or not taking the drug at all). ${ }^{3,4}$ Health care professionals worldwide are asking why patients do not take the drugs as prescribed, despite the perception that the treatment is offered in consensus with the patient. In fact, the importance of establishing an agreement between the patient and the health care professional concerning the treatment (ie, concordance), has been increasingly discussed during the last decades and is presumed to be one of the keys to improved adherence. ${ }^{5}$
Correspondence: Lena Thunander Sundbom

University of Gävle, Faculty of Health and Occupational Studies, 80I 76 Gävle, Sweden

Tel +46705 536316

Email lts@hig.se 
Despite a great deal of effort being expended to find out why patients are nonadherent, this complex phenomenon is still not fully understood. In order to improve adherence, it is necessary to understand the reasons behind NA. Previous studies have shown that adherence is affected by sociodemographic (eg, age and sex) and socioeconomic factors, the patient's attitude towards drugs, their relationship with the health care professional, patient characteristics, the prescribing of complicated dosage regimens, and the development of adverse drug reactions (ADRs)..$^{1,2,4,6-8}$ Moreover, psychological distress, such as anxiety and depression, which affect cognitive function and health behavior, also influence adherence. ${ }^{9}$ Anxiety and depression are associated with increased morbidity and mortality from somatic diseases and poor medication adherence is considered one of the causes for this. ${ }^{9}$ Psychological distress is frequently seen in primary care,$^{10}$ often appearing concomitantly with somatic disease; one in three patients who consult a health care professional for somatic health problems also suffer from anxiety and/or depression. ${ }^{11}$ However, many who experience symptoms of psychological distress do not fulfill the criteria for psychiatric disease and their problems will in many cases remain unnoticed. ${ }^{12-14}$

The purpose of this study was to evaluate the associations between self-reported symptoms of anxiety and/or depression, NA behaviors, and reasons for NA to medication regimens.

\section{Material and methods}

\section{Participants}

A random sample of the Swedish population, aged 18-84 years $(\mathrm{n}=7,985)$, received a postal questionnaire and two reminders during 2004-2005. The data were collected by Statistics Sweden (SCB, a Swedish government agency), which is responsible for the population register in Sweden. SCB linked the returned questionnaires with relevant sociodemographic information (age, sex) and deleted the personal identification numbers to ensure anonymity. The questionnaire response rate was $61.1 \%(n=4,875 ; n=4,709$ remained after deleting data from participants with missing values), and was greater among women $(65.2 \%, \mathrm{n}=2,549)$ than among men $(56.8 \%$, $\mathrm{n}=2,160)$. Of the participants, $59.5 \%(\mathrm{n}=2,802)$ reported prescription drug use during the two weeks before receiving the questionnaire; further analyses in this paper concern only these participants (Table 1).

\section{Questionnaire}

\section{Assessment of drug use and adherence}

The questionnaire assessing drug use and adherence was based on the Swedish Survey of Living Conditions ${ }^{15}$ and on general knowledge of the field. ${ }^{16}$ Participants who reported use of at least one prescription drug from a list of alternatives (antihypertensives, diuretics, antidiabetics, asthma treatment, analgesics, antidepressants, anxiolytics, hypnotics, antibiotics, dermatological drugs and contraceptives) were classified as users. The participants were asked to select the types of NA behavior (Table 2) and the reasons for this behavior (Table 3) as appropriate from the supplied lists of alternatives. Each participant could choose as many options as were relevant. Users who reported one or more types of NA behavior were classified as nonadherent. Nonadherent behavior was classified as unintentional (forgetting to take the drug) or intentional (the rest of the alternatives).

\section{Assessment of anxiety and depression}

Symptoms of anxiety and depression were assessed using the Hospital Anxiety and Depression Scale (HADS), ${ }^{17}$

Table I Number of participants in the study population, including prescription drug users ${ }^{\mathrm{a}}$ and nonadherent ${ }^{\mathrm{b}}$ prescription drug users, by sex and age

\begin{tabular}{|c|c|c|c|c|c|c|}
\hline \multirow{2}{*}{$\begin{array}{l}\text { Age } \\
\text { (years) }\end{array}$} & \multicolumn{3}{|l|}{ Men } & \multicolumn{3}{|l|}{ Women } \\
\hline & $\begin{array}{l}\text { Number } \\
\text { in study } \\
\text { population }\end{array}$ & $\begin{array}{l}\text { Number of users } \\
\text { (\% of total) }\end{array}$ & $\begin{array}{l}\text { Number of } \\
\text { nonadherent } \\
\text { users (\% of users) }\end{array}$ & $\begin{array}{l}\text { Number in study } \\
\text { population }\end{array}$ & $\begin{array}{l}\text { Number } \\
\text { of users } \\
\text { (\% of total) }\end{array}$ & $\begin{array}{l}\text { Number of } \\
\text { nonadherent } \\
\text { users (\% of users) }\end{array}$ \\
\hline $18-34$ & 452 & 107 (23.7) & 78 (72.9) & 610 & $369(60.5)$ & $287(77.8)$ \\
\hline $35-44$ & 363 & $128(35.3)$ & $105(82.0)$ & 466 & $264(56.7)$ & $212(80.3)$ \\
\hline $45-54$ & 388 & I 73 (44.6) & $|2|(69.9)$ & 442 & $264(59.7)$ & 201 (76.I) \\
\hline $55-64$ & 456 & $287(62.9)$ & $201(70.0)$ & 472 & $352(74.6)$ & $226(64.2)$ \\
\hline $65-74$ & 319 & $235(73.7)$ & $128(54.5)$ & 337 & $272(80.7)$ & $138(50.7)$ \\
\hline $75-84$ & 182 & I 54 (84.6) & $76(49.4)$ & 222 & 197 (88.7) & 87 (44.2) \\
\hline Total & 2,160 & $\mathrm{I}, 084(50.2)$ & 709 (65.4) & 2,549 & I,7। 8 (67.4) & $\mathrm{I}, \mathrm{I5I}(67.0)$ \\
\hline
\end{tabular}

Notes: ${ }^{2}$ Drug users were defined as participants who reported use of one or more prescription drug during the two weeks before receiving the questionnaire; ${ }^{\circ}$ nonadherent drug users were defined as participants who responded positively to any of the nonadherent behaviors in the questionnaire (forgot to take the medication, filled prescription but did not use medication, changed dosage on own accord, discontinued a medical treatment, did not fill prescription). 
Table 2 Percentages of prescription drug users with or without symptoms of anxiety and/or depression who reported various types of nonadherent behavior

\begin{tabular}{|c|c|c|c|c|c|c|c|c|c|c|c|c|}
\hline \multirow{2}{*}{$\begin{array}{l}\text { Nonadherent } \\
\text { behavior }^{\mathrm{a}}\end{array}$} & \multicolumn{4}{|c|}{ Men $\mathbf{n}=702$} & \multicolumn{4}{|c|}{ Women $\mathrm{n}=\mathrm{I}, \mathbf{1} 38$} & \multicolumn{4}{|c|}{ All $n=I, 840$} \\
\hline & $\begin{array}{l}\text { Anx } \\
n=76\end{array}$ & $\begin{array}{l}\text { Depr } \\
n=34\end{array}$ & $\begin{array}{l}\text { Both } \\
n=68\end{array}$ & $\begin{array}{l}\text { None } \\
n=524\end{array}$ & $\begin{array}{l}\text { Anx } \\
n=159\end{array}$ & $\begin{array}{l}\text { Depr } \\
n=49\end{array}$ & $\begin{array}{l}\text { Both } \\
n=|2|\end{array}$ & $\begin{array}{l}\text { None } \\
n=809\end{array}$ & $\begin{array}{l}\text { Anx } \\
n=235\end{array}$ & $\begin{array}{l}\text { Depr } \\
n=83\end{array}$ & $\begin{array}{l}\text { Both } \\
n=189\end{array}$ & $\begin{array}{l}\text { None } \\
\mathrm{n}=1,333\end{array}$ \\
\hline $\begin{array}{l}\text { Any nonadherence } \\
\text { (unintentional } \\
\text { or intentional) }\end{array}$ & 81.7 & 64.2 & 81.9 & 62.2 & 75.4 & 83.1 & 79.1 & 63.7 & 77.3 & 74.1 & 80.1 & 63.1 \\
\hline $\begin{array}{l}\text { Unintentional } \\
\text { nonadherence } \\
\text { (forgot to take } \\
\text { the medication) }\end{array}$ & 64.5 & 49.1 & 73.5 & 48.3 & 57.3 & 64.4 & 57.5 & 46.2 & 59.5 & 57.1 & 63.1 & 47.1 \\
\hline $\begin{array}{l}\text { Any intentional } \\
\text { nonadherence } \\
\text { (see below) }\end{array}$ & 58.1 & 47.2 & 60.2 & 38.0 & 57.3 & 67.8 & 64.7 & 43.6 & 57.6 & 58.0 & 63.1 & 41.4 \\
\hline $\begin{array}{l}\text { Changed dosage } \\
\text { on own accord }\end{array}$ & 33.3 & 22.6 & 38.6 & 18.5 & 25.6 & 32.2 & 29.4 & 13.4 & 28.0 & 27.7 & 32.6 & 15.4 \\
\hline $\begin{array}{l}\text { Discontinued a } \\
\text { medical treatment }\end{array}$ & 33.3 & 18.9 & 26.5 & 17.3 & 31.3 & 37.3 & 29.4 & 21.7 & 31.9 & 28.6 & 28.4 & 19.9 \\
\hline $\begin{array}{l}\text { Filled a prescription } \\
\text { but did not take } \\
\text { the medication }\end{array}$ & 30.1 & 22.6 & 20.5 & 17.6 & 35.6 & 35.6 & 31.4 & 23.9 & 33.9 & 29.5 & 27.5 & 21.4 \\
\hline $\begin{array}{l}\text { Did not have a } \\
\text { prescription filled }\end{array}$ & 22.6 & 28.3 & 31.3 & 15.3 & 29.4 & 33.9 & 39.9 & 19.3 & 27.3 & 31.2 & 36.9 & 17.7 \\
\hline
\end{tabular}

Notes: Missing values, men $n=7$, women $n=13$. aSeveral choices could be made by the same participant.

Abbreviations: Anx, anxiety; Depr, depression.

a self-report questionnaire (that has been validated in primary care as well as in the general population), ${ }^{18}$ screening for anxiety and depression symptoms during the previous week. In this study, a cut-off level of $\geq 8$ was used (ie, at least 8 of the possible 21) to achieve optimal balance between sensitivity and specificity. ${ }^{18}$ Participants were divided into groups according to the presence of symptoms of anxiety, depression, or both, or the absence of these symptoms.

\section{Statistics}

The Statistical Analysis System (SAS ${ }^{\circledR} 9.2$, Cary, NC, USA) was used to perform logistic regression analyses (The LOGISTIC Procedure) to evaluate the associations between

Table 3 Percentages of prescription drug users with or without symptoms of anxiety and/or depression who gave various reasons ${ }^{\mathrm{a}}$ for nonadherence

\begin{tabular}{|c|c|c|c|c|c|c|c|c|c|c|c|c|}
\hline \multirow{2}{*}{$\begin{array}{l}\text { Reasons for } \\
\text { nonadherence }\end{array}$} & \multicolumn{4}{|c|}{ Men $n=702$} & \multicolumn{4}{|c|}{ Women $n=1,138$} & \multicolumn{4}{|c|}{ All $n=I, 840$} \\
\hline & $\begin{array}{l}\text { Anx } \\
n=76\end{array}$ & $\begin{array}{l}\text { Depr } \\
\mathrm{n}=\mathbf{3 4}\end{array}$ & $\begin{array}{l}\text { Both } \\
n=68\end{array}$ & $\begin{array}{l}\text { None } \\
n=524\end{array}$ & $\begin{array}{l}\text { Anx } \\
n=159\end{array}$ & $\begin{array}{l}\text { Depr } \\
n=49\end{array}$ & $\begin{array}{l}\text { Both } \\
n=|2|\end{array}$ & $\begin{array}{l}\text { None } \\
\mathrm{n}=\mathbf{8 0 9}\end{array}$ & $\begin{array}{l}\text { Anx } \\
n=235\end{array}$ & $\begin{array}{l}\text { Depr } \\
n=83\end{array}$ & $\begin{array}{l}\text { Both } \\
n=189\end{array}$ & $\begin{array}{l}\text { None } \\
n=1,333\end{array}$ \\
\hline $\begin{array}{l}\text { Did not need } \\
\text { the medication }\end{array}$ & 17.2 & 11.3 & 13.3 & 12.2 & 16.6 & 15.3 & 15.0 & 16.6 & 16.8 & 13.4 & 14.4 & 14.9 \\
\hline Recovered & 19.4 & 13.2 & 10.8 & 13.8 & 17.1 & 17.0 & 13.1 & 13.0 & 17.8 & 15.2 & 12.3 & 13.3 \\
\hline $\begin{array}{l}\text { Developed } \\
\text { unpleasant } \\
\text { adverse drug } \\
\text { reactions }\end{array}$ & 5.4 & 3.8 & 14.5 & 4.8 & 10.9 & 15.3 & 20.3 & 9.4 & 9.2 & 9.8 & 18.2 & 7.5 \\
\hline $\begin{array}{l}\text { Had a fear of } \\
\text { potential adverse } \\
\text { drug reactions }\end{array}$ & 16. I & 9.4 & 8.4 & 4.0 & 17.5 & 8.5 & 16.7 & 7.0 & 17.1 & 8.9 & 14.0 & 5.8 \\
\hline $\begin{array}{l}\text { Treatment was } \\
\text { not effective }\end{array}$ & 14.0 & 3.8 & 16.9 & 5.9 & 9.0 & 11.9 & 19.0 & 6.9 & 10.5 & 8.0 & 18.2 & 6.5 \\
\hline $\begin{array}{l}\text { Wanted to save } \\
\text { money }\end{array}$ & 5.4 & 5.7 & 8.4 & 2.4 & 7.1 & 6.8 & 8.5 & 1.8 & 6.6 & 6.3 & 8.5 & 2.0 \\
\hline
\end{tabular}

Notes: Missing values men $n=7$, women $n=13$. aSeveral choices could be made by the same participant.

Abbreviations: Anx, anxiety; Depr, depression. 
symptoms of anxiety and/or depression, self-reported NA, and the reasons for NA. Odds ratios (OR) with 95\% confidence intervals (CI) were obtained.

\section{Ethics}

The study complied with ethical research requirements, as approved by the SCB Ethics Committee, in concordance with Swedish legislation before 2008. ${ }^{19}$

\section{Results}

Table 1 provides an overview of the study population by sex and age. In total, $50.2 \%$ of the men $(n=1,084)$ and $67.4 \%$ of the women $(n=1,718)$ reported use of at least one prescription drug during the previous two weeks; in total $66.4 \%$ (men; $\mathrm{n}=709,65.4 \%$, women; $\mathrm{n}=1,151,67.0 \%$ ) of the users were classified as nonadherent (either unintentional or intentional). The decrease in NA by age was statistically significant for men and for women (chi-square: $P<0.0001,5 d f$ for men as well as women).

A summary of the percentage of participants with or without symptoms of anxiety and/or depression who reported any of the NA behavior types is presented in Table 2, while the reasons for the NA are presented in Table 3 . When the different types of NA behavior were analyzed using logistic regression (Table 4), symptoms of anxiety and/or depression were associated with unintentional and, to a greater extent, intentional NA. The associations between the reasons for NA and the symptoms of anxiety and/or depression were also analyzed using logistic regression (Table 5). For example, symptoms of depression, independently or in combination with anxiety, were associated with the development of ADRs, and symptoms of anxiety, independently or in combination with depression, were associated with a fear of developing ADRs. As can be seen, the associations between symptoms of anxiety and/or depression and NA varied somewhat between men and women.

\section{Discussion}

\section{Nonadherence and its causes}

We found associations between symptoms of anxiety and/or depression and NA. These associations occurred with both intentional and unintentional NA, with a stronger average association for intentional NA. This suggests that patients are likely to make an active decision to be nonadherent when they are experiencing symptoms of anxiety and/or depression. There seem to be a lack of studies examining specific intentional and unintentional types of NA behavior. However, most previous studies have found psychological distress to be
Table 4 Logistic regression analyses associating symptoms of anxiety and/or depression with various types of nonadherent behavior

\begin{tabular}{|c|c|c|c|c|c|c|}
\hline & \multicolumn{2}{|l|}{ Men } & \multicolumn{2}{|c|}{ Women } & \multicolumn{2}{|l|}{ All } \\
\hline & $\mathbf{R}^{\mathbf{a}}$ & $95 \% \mathrm{Cl}$ & OR $^{\mathbf{a}}$ & $95 \% \mathrm{Cl}$ & $\mathbf{O R}^{\mathrm{b}}$ & $5 \% \mathrm{Cl}$ \\
\hline & \multicolumn{6}{|c|}{ Any nonadherence (unintentional or intentional) } \\
\hline mate & 2.44 & $1.45-4.09$ & 1.37 & $1.00-1.88$ & 1.61 & 1.2 \\
\hline Depr & 43 & & 2.37 & & & \\
\hline \multirow[t]{2}{*}{ Both } & .08 & $1.28-3.37$ & 2.01 & 1.39-2.89 & 2.03 & $|.52-2.7|$ \\
\hline & \multicolumn{6}{|c|}{$\begin{array}{l}\text { Unintentional nonadherence (forgot to take the } \\
\text { medication) }\end{array}$} \\
\hline Anxiety & 1.56 & $1.02-2.38$ & 1.25 & $0.94-1.66$ & 1.33 & $1.06-1.69$ \\
\hline Depre & 10 & 0.6 & 1.92 & & 1.45 & 2.06 \\
\hline \multirow[t]{2}{*}{ Both } & 2.22 & $|.45-3.4|$ & 1.46 & I.07-1.97 & 1.67 & I. \\
\hline & \multicolumn{6}{|c|}{ Any intentional nonadherence (see below) } \\
\hline Ans & 2.02 & 1.32 & 1.49 & 1.12 & 1.62 & 2.05 \\
\hline Dep & 32 & & 2 & & 0 & \\
\hline \multirow[t]{2}{*}{ Both } & 1.80 & 1.19 & 2.22 & 1.62 & 2.06 & 1.6 \\
\hline & \multicolumn{6}{|c|}{ Changed dosage of own accord } \\
\hline Anxiety & 2.30 & $1.47-3.60$ & 1.80 & 1.27 & 1.94 & $1.4 \varepsilon$ \\
\hline Depre & 19 & 1.2 & 2.61 & 1.4 & 2.36 & 3.50 \\
\hline \multirow[t]{2}{*}{ Both } & 2.02 & $1.30-3.15$ & 2.55 & $|.80-3.6|$ & 2.32 & $1.76-3.04$ \\
\hline & \multicolumn{6}{|c|}{ Discontinued a medical treatment } \\
\hline Anxi & 2.60 & $1.65-4.10$ & I.7I & $1.26-2.32$ & 1.92 & 1.4 \\
\hline Depressi & 2.61 & & 2. & & 2.41 & 1.6 \\
\hline \multirow[t]{2}{*}{ Both } & 1.52 & $0.94-2.45$ & 1.60 & I.14-2.22 & 1.58 & 1.20 \\
\hline & \multicolumn{6}{|c|}{ Filled a prescription but did not take the medication } \\
\hline Anxiety & 1.48 & $0.92-2.38$ & 1.30 & $0.95-1.76$ & 1.33 & $1.03-1.73$ \\
\hline Depressio & 1.58 & $0.88-2.84$ & 2.22 & $1.33-3.69$ & 1.92 & $1.32-2.82$ \\
\hline \multirow[t]{2}{*}{ Both } & 1.08 & $0.65-1.77$ & 1.54 & $1.12-2.12$ & 1.39 & $1.06-1.8$ \\
\hline & \multicolumn{6}{|c|}{ Did not have a prescription filled } \\
\hline Anx & 1.45 & $0.88-2$ & 1.43 & $1.03-$ & 1.43 & $1.09-1.88$ \\
\hline Depression & 2.73 & I.53-4.89 & 2.38 & I.38-4.09 & 2.55 & I.72.3.80 \\
\hline Both & 1.87 & $1.17-2.99$ & 2.22 & $1.59-3.08$ & 2.10 & $1.60-2.74$ \\
\hline
\end{tabular}

Notes: aControlling for age; ${ }^{b}$ controlling for age and sex.

Abbreviations: $\mathrm{OR}$, odds ratio; $\mathrm{Cl}$, confidence interval.

associated with poor adherence in general. ${ }^{9,20}$ Various reasons for this association have been suggested. For example, reduced energy and feelings of hopelessness could create more negative expectations of treatment outcomes. ${ }^{9}$ Also, decreased levels of cognitive function and lack of social support have been found to be associated with mood disorders and these could affect medication adherence. ${ }^{9}$ In addition, while psychological distress results in increased healthcare contact, ${ }^{9,20}$ it is also likely to result in the prescription of more medications, and hence more opportunities to be nonadherent. However, while depression has been found to be a risk factor for NA, the results are somewhat conflicting in studies investigating anxiety and comorbidity. ${ }^{9,20}$ The explanation for this is unclear, but it is possibly due to the heterogeneity of anxiety symptoms. ${ }^{9}$ To be anxious about one's health and worry about physical diseases can improve adherence while, on the other hand, a fear of unwanted effects from the drug can lead to poor adherence. 
Table 5 Logistic regression analyses associating symptoms of anxiety and/or depression with various reasons for nonadherence

\begin{tabular}{|c|c|c|c|c|c|c|}
\hline & \multicolumn{2}{|l|}{ Men } & \multicolumn{2}{|c|}{ Women } & \multicolumn{2}{|l|}{ All } \\
\hline & $\mathbf{O R}^{\mathbf{a}}$ & $95 \% \mathrm{Cl}$ & OR $^{\mathbf{a}}$ & $95 \% \mathrm{Cl}$ & $\mathbf{O R}^{\mathbf{b}}$ & $95 \% \mathrm{Cl}$ \\
\hline & \multicolumn{6}{|c|}{ Did not need the medication } \\
\hline Anxiety & 1.19 & $0.67-2.11$ & 0.95 & $0.66-1.37$ & 1.01 & $0.74-1.37$ \\
\hline Depression & 1.41 & $0.68-2.92$ & 0.86 & $0.43-1.75$ & 1.06 & $0.64-1.75$ \\
\hline \multirow[t]{2}{*}{ Both } & 1.05 & $0.59-$ & 0.72 & $0.47-1.10$ & 0.81 & $0.57-1.14$ \\
\hline & \multicolumn{6}{|c|}{ Recovered } \\
\hline Anxiety & 1.10 & $0.63-1.90$ & 1.24 & $0.85-1.82$ & 1.18 & $0.87-1.6 \mid$ \\
\hline Depression & 1.46 & $0.74-2.87$ & 2.32 & $1.27-4.26$ & 1.87 & $1.19-2.93$ \\
\hline Both & 0.63 & $0.33-1.17$ & 0.95 & $0.6 \mathrm{I}-\mathrm{I} .48$ & 0.82 & $0.57-1.17$ \\
\hline & \multicolumn{6}{|c|}{ Developed unpleasant adverse drug reactions } \\
\hline Anxiety & 1.70 & $0.72-4.02$ & 1.12 & $0.7 I-I .77$ & 1.21 & $0.8 \mathrm{I}-1.8 \mathrm{I}$ \\
\hline Depression & 3.03 & $1.33-6.89$ & 2.35 & $1.23-4.48$ & 2.60 & $|.57-4.3|$ \\
\hline Both & 2.73 & $1.35-5.53$ & 2.21 & $\mid .47-3.31$ & 2.32 & $1.63-3.29$ \\
\hline & \multicolumn{6}{|c|}{ Had a fear of potential adverse drug reactions } \\
\hline Anxiety & 3.07 & $1.55-6.08$ & 2.44 & $1.60-3.72$ & 2.60 & $\mathrm{I} .8 \mathrm{I}-3.72$ \\
\hline Depression & 2.40 & $0.96-6.03$ & 1.08 & $0.42-2.77$ & 1.55 & $0.8 \mathrm{I}-2.98$ \\
\hline \multirow[t]{2}{*}{ Both } & 1.96 & $0.93-4.16$ & 2.91 & $1.90-4.45$ & 2.67 & $1.85-3.85$ \\
\hline & \multicolumn{6}{|c|}{ Treatment was not effective } \\
\hline Anxiety & 1.83 & $0.93-3.60$ & 1.03 & $0.61-1.75$ & 1.26 & $0.83-1.90$ \\
\hline Depression & 1.58 & $0.64-3.90$ & 2.48 & $1.20-5.10$ & 2.07 & $1.18-3.62$ \\
\hline \multirow[t]{2}{*}{ Both } & 2.33 & $1.25-4.35$ & 2.72 & $1.77-4.18$ & 2.60 & $1.83-3.70$ \\
\hline & \multicolumn{6}{|c|}{ Wanted to save money } \\
\hline Anxiety & 1.88 & $0.7 \mathrm{I}-5.0 \mathrm{I}$ & 2.14 & $1.04-4.43$ & 2.04 & I.14-3.64 \\
\hline Depression & 1.45 & $0.32-6.52$ & 3.45 & $1.13-10.49$ & $2.4 I$ & $0.99-5.86$ \\
\hline Both & 3.38 & $1.45-7.73$ & 4.10 & $2.12-7.95$ & 3.79 & $2.26-6.33$ \\
\hline
\end{tabular}

Notes: aControlling for age; 'controlling for age and sex.

Abbreviations: $\mathrm{OR}$, odds ratio; $\mathrm{Cl}$, confidence interval.

There appear also to be a lack of studies examining the correlations between the reasons for NA and anxiety and/ or depression symptoms. The presence or fear of ADRs emerged as an important factor for NA in our study: anxiety and comorbid anxiety and depression symptoms were associated with a fear of developing ADRs and depression and comorbid anxiety and depression symptoms were associated with the actual development of ADRs. The associations between anxiety and comorbid anxiety and depression symptoms and NA based on a fear of developing ADRs, were possibly associated with anxiety-related increased concerns about the medication. The possible increased use of medications associated with greater health care utilization by patients with psychological distress ${ }^{9,20}$ could mean that these patients have a previous history of ADRs that could increase the expectation that more would develop.

The reason behind the association of the development of ADRs with depression or comorbid anxiety and depression is a bit unclear; however, one could speculate that depression might be more likely to lead to sensitivity to drugs, and thus development of ADRs, than anxiety. Also, one has to consider the timing of the depression; the depression symptoms might have developed as a result of the ADRs. Moreover, again, increased health care utilization could lead to increased consumption of drugs, including psychotropic drugs, and, subsequently, more ADRs.

Men and women have different health behaviors ${ }^{21}$ and also different attitudes toward drugs ${ }^{22,23}$ and have in previous studies been found to have different NA behaviors and different reasons for NA. ${ }^{1,2,4}$ As regards men and women with anxiety and/or depression, knowledge about the effects of sex on adherence is lacking. However, in a review on anxiety disorders, the majority of the available studies did not find sex differences between adherent and nonadherent patients. ${ }^{20}$ Although our study was not specifically designed to investigate the effects of sex, we found some interesting differences that deserve some comments. For example, concerning unintentional NA, an association was found with depression among women but not among men. The reverse case was found in patients suffering from anxiety. Thus, depression did not seem to affect men's ability to remember medication and, in contrast, anxiety did not affect women's ability. Amongst reasons for NA, perceived recovery from disease and ineffective treatment were associated with depression in women only. However, speculation on these outcomes is not appropriate. Instead, we hope the results can serve as inspiration for future research in this complicated field.

\section{Implications for health care professionals}

This study evaluates the association between two very common, yet not readily apparent, problems in health care professional's everyday reality: psychological distress and NA. While patients with symptoms of anxiety and/or depression often visit their health care professional, the majority of these visits are for somatic symptoms. ${ }^{11}$ As a consequence, the psychological distress may not be revealed. ${ }^{12-14}$ This study indicates that patients experiencing symptoms of psychological distress are at increased risk of NA and would thus benefit from extra attention. It is important, therefore, to watch for early indications of psychological distress in order to identify possible future NA. A negative spiral could plausibly be initiated if the psychological distress is not discovered: poor physical health can cause poor mental health, which can result in NA, and NA can result in even poorer physical health, and even worse mental health, and so on. ${ }^{9}$ Consequently, health care professionals are advised to be conscious of the connection between psychological distress and NA. When patients obtain relief from their psychological distress, improvement in medication adherence is possible. 
By identifying the causes of NA in patients with anxiety and/or depression, health care professionals should be able to develop strategies to improve adherence. Patients experiencing symptoms of anxiety and/or depression could benefit from a detailed discussion about potential or perceived ADRs. It is essential to explain not only the benefits of the treatment but also any negative aspects such as the potential development of ADRs in order for the patients to retain trust in their health care professional. If they are left to subsequently discover the potential for or development of ADRs by themselves, without having been warned, mistrust of the health care professional could result in NA. In order to improve adherence to medication regimens, the decision concerning drug treatment should be based on an agreement between the patient and the health care professional, ie, concordance ${ }^{5}$ and a fear of ADRs should be taken seriously.

\section{Strengths and weaknesses}

The main strength of this study was the large sample size; all prescription drug users from a large random sample of the general Swedish population were included. The inclusion of questions on both the types and the underlying causes of NA behavior are another strength.

Some limitations of this work have to be considered. First, a cross-sectional design such as this does not allow assessment of causality derived from the results. Second, participation in the study was voluntary and there may have been selection biases. For example, non-responders were more likely to be men than women. One of the inclusion criteria was current prescription drug use, which also increased the proportion of women. It is also possible that people with current anxiety or depression symptoms would be less likely to respond, further biasing participant selection. Third, we did not control for confounding variables other than sex and age. Fourth, the HADS cut-off of $\geq 8$ used in the survey could have resulted in some false-positive cases. Nonetheless, we wanted to include all participants with at least mild symptoms and, moreover, the cut-off of 8 has been found to be the optimal threshold in other studies. ${ }^{18}$ Fifth, the assessment of adherence as well as anxiety and depression was based on self-reporting, which can be subject to bias. However, selfassessment performs well in screening procedures and has high accordance with other measurements. ${ }^{18,24}$

\section{Conclusion}

A cross-sectional design such as this does not allow assessment of causality derived from the results. However, the results indicate that patients experiencing symptoms of psychological distress are at increased risk of NA, especially intentional NA, and could therefore benefit from extra attention from the health care professionals. Patients with symptoms of anxiety and/or depression should be identified and monitored for the development and/or fear of ADRs, in order to improve adherence to medication regimens. Hopefully, this study can provide ideas for future studies in this field.

\section{Acknowledgments}

The study was funded by the National Corporation of Swedish Pharmacies Research Foundation.

\section{Disclosure}

The authors report no conflicts of interest in this work.

\section{References}

1. Vermeire E, Hearnshaw H, Van Royen P, Denekens J. Patient adherence to treatment: three decades of research. A comprehensive review. J Clin Pharm Ther. 2001;26:331-342.

2. Sabaté E, Adherence to long-term therapies: evidence for action. Geneva, Switzerland: WHO; 2003.

3. Lehane $\mathrm{E}, \mathrm{McC}$ arthy $\mathrm{G}$. Intentional and unintentional medication non-adherence: a comprehensive framework for clinical research and practice? A discussion paper. Int J Nurs Stud. 2007;44:1468-1477.

4. Thunander Sundbom L, Bingefors K. Women and men report different behaviours in, and reasons for medication non-adherence: a nationwide Swedish survey. Pharm Pract. 2012;10:207-221.

5. Fraser S. Concordance, compliance, preference or adherence. Patient Prefer Adherence. 2010;4:95-96.

6. Wilke T, Muller S, Morisky DE. Toward identifying the causes and combinations of causes increasing the risks of nonadherence to medical regimens: combined results of two German self-report surveys. Value Health. 2011;14:1092-1100.

7. Åkerblad A-C, Bengtsson F, Holgersson M, von Knorring L, Ekselius L. Identification of primary care patients at risk of nonadherence to antidepressant treatment. Patient Prefer Adherence. 2008;2:379-386.

8. McHorney CA, Gadkari AS. Individual patients hold different beliefs to prescription medications to which they persist vs nonpersist and persist vs nonfulfill. Patient Prefer Adherence. 2010;4:187-195.

9. DiMatteo MR, Lepper HS, Croghan TW. Depression is a risk factor for noncompliance with medical treatment: meta-analysis of the effects of anxiety and depression on patient adherence. Arch Intern Med. 2000;160:2101-2107.

10. Rosendal M, Vedsted P, Sparle Christensen K, Moth G. Psychological and social problems in primary care patients - general practitioners' assessment and classification. Scand J Prim Health Care. 2013;31: $43-49$.

11. Stordal E, Bjelland I, Dahl AA, Mykletun A. Anxiety and depression in individuals with somatic health problems. The Nord-Trondelag Health Study (HUNT). Scand J Prim Health Care. 2003;21:136-141.

12. Karlsson $H$, Lehtinen $V$, Joukamaa $M$. Are frequent attenders of primary health care distressed? Scand J Prim Health Care. 1995;13:32-38.

13. Østergaard SD, Foldager L, Allgulander C, et al. Psychiatric caseness is a marker of major depressive episode in general practice. Scand $J$ Prim Health Care. 2010;28:211-215.

14. Lecrubier Y. Widespread underrecognition and undertreatment of anxiety and mood disorders: results from 3 European studies. J Clin Psychiatry. 2007;68:36-41.

15. Statistics Sweden. Living conditions. Appendix 13. Technical report for surveys conducted during 1984-1989. Surveys of Living Conditions. Örebro: SCB- Tryck, 1992. 
16. Morisky DE, Green LW, Levine DM. Concurrent and predictive validity of a self-reported measure of medication adherence. Med Care. 1986;24:67-74.

17. Zigmond AS, Snaith RP. The hospital anxiety and depression scale. Acta Psychiatr Scand. 1983;67:361-370.

18. Bjelland I, Dahl AA, Tangen Haug T, Neckelmann D. The validity of the Hospital Anxiety and Depression Scale. An updated literature review. J Psychosom Res. 2002;52:69-77.

19. Vetting the ethics of research involving humans. Available from: http:// www.epn.se/start/startsida.aspx. Accessed May 30, 2013.

20. Santana L, Fontenelle LF. A review of studies concerning treatment adherence of patients with anxiety disorders. Patient Prefer Adherence. 2011;5:427-439.
21. Verbrugge LM. Gender and health: an update on hypotheses and evidence. J Health Soc Behav. 1985;26(3):156-182.

22. Pound P, Britten N, Morgan M, et al. Resisting medicines: a synthesis of qualitative studies of medicine taking. Soc Sci Med. 2005;61(1): $133-155$.

23. Isacson D, Bingefors $\mathrm{K}$. Attitudes towards drugs - a survey in the general population. Pharm World Sci. 2002;24(3):104-110.

24. Garber MC, Nau DP, Erickson SR, Aikens JE, Lawrence JB. The concordance of self-report with other measures of medication adherence: a summary of the literature. Med Care. 2004;42:649-652.

\section{Publish your work in this journal}

Patient Preference and Adherence is an international, peer-reviewed, open access journal focusing on the growing importance of patient preference and adherence throughout the therapeutic continuum. Patient satisfaction, acceptability, quality of life, compliance, persistence and their role in developing new therapeutic modalities and compounds to optimize clinical outcomes for existing disease states are major areas of interest. This journal has been accepted for indexing on PubMed Central. The manuscript management system is completely online and includes a very quick and fair peer-review system. Visit http://www.dovepress.com/ testimonials.php to read real quotes from published authors.

Submit your manuscript here: http://www.dovepress.com/patient-preference-and-adherence-journal 